\title{
HIGH TEMPERATURE OXIDATION OF TI-6AL-4V ALLOY FABRICATED BY ADDITIVE MANUFACTURING. INFLUENCE ON MECHANICAL PROPERTIES.
}

\author{
Antoine CASAdEBAIGT $\left({ }^{1,2}\right)$, Daniel MONCEAU $\left({ }^{1}\right)$, Jonathan HUGUES $\left({ }^{2}\right)$
}

\author{
1) CIRIMAT, Université de Toulouse, CNRS, -ENSIACET, 4 allée Emile Monso, 31030 TOULOUSE
}

(2) IRT SAINT EXUPERY, Bâtiment B612 - 5 rue TARFAYA - 31400 TOULOUSE

antoine.casadebaigt@ensiacet.fr

\section{$\underline{\text { Abstract }}$}

Titanium alloys, such as Ti-6Al-4V alloy, fabricated by additive manufacturing processes is a winning combination in the aeronautic field. Indeed, the high specific mechanical properties of titanium alloys with the optimized design of parts allowed by additive manufacturing should allow aircraft weight reduction. But, the long term use of Ti- $6 \mathrm{Al}-4 \mathrm{~V}$ alloy is limited to $315{ }^{\circ} \mathrm{C}$ due to high oxidation kinetics above this temperature [1]. The formation of an oxygen diffusion zone in the metal and an oxide layer above it may reduce the durability of titanium parts leading to premature failure [2,3]. In this study, Ti-6Al-4V alloy was fabricated by Electron Beam Melting (EBM). As built microstructure evolutions after Hot Isostatic Pressure (HIP) treatment at 920 ${ }^{\circ} \mathrm{C}$ and $1000 \mathrm{bar}$ for $2 \mathrm{~h}$ were investigated. As built microstructure of Ti-6Al-4V fabricated by EBM was composed of Ti- $\alpha$ laths in a Ti- $\beta$ matrix. High temperature oxidation of Ti-6Al- $4 \mathrm{~V}$ alloy at $600{ }^{\circ} \mathrm{C}$ of as-built and HIP-ed microstructures was studied. This temperature was chosen to increase oxidation kinetics and to study the influence of oxidation on tensile mechanical properties. In parallel, two other oxidation temperatures, i.e. $500^{\circ} \mathrm{C}$ and $550^{\circ} \mathrm{C}$ allowed to access to the effect of temperature on long-term oxidation.

\section{$\underline{\text { Introduction }}$}

In the aeronautic field, reducing flight consumption of planes is one of the main objectives. Using lighter metals such as titanium alloys or additively manufactured parts with complex geometry are of interest. Ti-6Al-4V alloy ( $\mathrm{wt} \%$.) is the most used titanium alloy in the aeronautic field and many studies investigating the development of this alloy fabricated by additive manufacturing were published [4-6]. The Electron Beam Melting (EBM) process is a powder bed fusion process used only for conductor materials [5]. The electron beam works in a vacuum environment and is focused on the powder bed using electromagnetic lenses [7]. To avoid the sputtering of the powder, a pre-heating step is used before melting the metallic powder, leading to maintain the powder around 700
${ }^{\circ} \mathrm{C}$. Once the melting step is done, the powder bed is recoated by another powder bed and the operation is repeated until the final part is built [5, 6, 8-11]. For Ti-6 Al-4V alloy, the high cooling rates ${ }^{\circ} \mathrm{C}$. Once the melting step is done, the powder bed is recoated by another powder bed and the operation is repeated until the final part is built [5, 6, 8-11]. For Ti-6 Al-4V alloy, the high cooling rates and the high building temperature induce a thin lamellar Ti- $\alpha$ phase into a Ti- $\beta$ matrix microstructure. Hot Isostatic Pressing (HIP) treatment at $920{ }^{\circ} \mathrm{C}$ during $2 \mathrm{~h}$ at $100 \mathrm{MPa}$ is commonly used on additively manufactured Ti-6Al-4V alloy to close pores and modify microstructure and mechanical properties [12]. Inside or close to plane's engines, oxidation behaviour of metal alloys is of interest. Kakehi et al. showed the modification of tensile properties induced by oxidation [13]. Due to the increase of engines working temperatures in order to increase their efficiency, titanium alloys may face higher oxidation rates. The use of titanium alloys is limited to low temperature areas due to their high oxidation kinetics above $550^{\circ} \mathrm{C}$. Temperature is even lower for Ti-6Al-4V i.e. $315^{\circ} \mathrm{C}[1]$. Reacting with air, titanium alloys form an oxide and dissolve oxygen in the metallic matrix. The diffusion of the oxygen in the metallic matrix induces a modification of mechanical properties leading to premature failure [13]. Oxidation behaviour of Ti-6Al-4V alloy was essentially reported at temperatures between 600 and $1100{ }^{\circ} \mathrm{C}$ and for durations up to $300 \mathrm{~h}[14-19]$. Sefer $e t$ al. and Ciszak et al. published ones of the few studies characterizing the oxidation behaviour of Ti-6Al-4V alloys at lower temperatures. Moreover, only two studies were published on the oxidation of titanium alloys Ti-5.5Al-3.4Sn-3.0Zr-0.7Mo-0.3Si-0.4Nb-0.35Ta wt $\%$ and Ti-6Al-4V wt $\%$ fabricated by additive manufacturing [20, 21]. No study was published on the influence of oxidation on mechanical properties of Ti-6Al-4V alloy fabricated by additive manufacturing. In the following paper, the oxidation behaviour of Ti-6Al-4V titanium alloy fabricated by EBM was studied.
Influence of HIP treatment on its oxidation behaviour was also assessed. Moreover, influence of oxidation on tensile properties of an EBM Ti-6Al-4V alloy was investigated.

\section{Materials and experiments}

Ti-6Al-4V alloy samples were fabricated by EBM using an Arcam Q20 + at IRT Saint Exupéry, France, using Arcam's parameters and theme 5.2.24. The building chamber was maintained in a partial vacuum of $4.10^{-3} \mathrm{mBar}$ and the building plate was pre-heated around $700{ }^{\circ} \mathrm{C}$. Fresh pre-alloyed Ti-6Al-4V grade 23 powder, plasma atomised by AP\&C, was used. The particles size was $45-$ $106 \mu \mathrm{m}$. The initial powder composition in weight percent was $6.35 \mathrm{Al}, 3.68 \mathrm{~V}, 0.19 \mathrm{Fe}, 0.01 \mathrm{C}, 0.02 \mathrm{~N}, 0.001 \mathrm{H}$ and $0.08 \mathrm{O}(\mathrm{at} \%: 10.75 \mathrm{Al}, 3.30 \mathrm{~V}, 0.16 \mathrm{Fe}, 0.04 \mathrm{C}, 0.07 \mathrm{~N}, 0.05 \mathrm{H}, 0.23 \mathrm{O})$. HIP was carried out on some samples at $920 \pm 10^{\circ} \mathrm{C}$ for $2 \mathrm{~h}-0+24$ min with a pressure of $1020 \pm 10$ bar. In addition, a rolled $\beta$-annealed Ti-6Al-4V alloy was used as comparison point. Microstructure investigations were performed with an Optical Microscope (OM) Nikon Eclipse MA200 after etching with Kroll reagent for 5 seconds. Finer observations were assessed with a Scanning Electron Microscope (SEM) FEI Quanta 450. Oxidation experiments at $600{ }^{\circ} \mathrm{C}$ were performed on $28 \times 28 \times 2 \mathrm{~mm}^{3}$ samples in a pre-heated Carbolite furnace LHT 6/60 with forced convection. In order to study the influence of surface roughness and HIP treatment on oxidation behaviour, 2 samples were kept as-built, 7 samples were polished with SiC abrasive paper of P600 grit size and 5 samples were HIP treated and polished with $\mathrm{SiC}$ abrasive paper of P600 grit size. Oxidation was characterized by weight gain, oxide layer and oxygen diffusion zone thicknesses measurements using a Sartorius LA $753200 \mathrm{D}$ balance with an accuracy of $\pm 20 \mu \mathrm{g}$, optical and electronic microscopes and microprobe (EPMA) respectively. EPMA measurements of oxygen content in titanium is difficult because of oxygen in the native oxide on its surface. In order to quantify this oxygen pollution, bulk oxygen concentration was measured on a cross section, with an average over 20 points. EPMA signal was corrected to bring back oxygen content between $800-1000 \mathrm{ppm}$ (in wt) in the bulk of the TA6V sample. Indeed, the value of 800 - 1000 ppm (in wt) is the oxygen concentration measured in EBM sample when using powder with an initial oxygen content of $800 \mathrm{ppm}$ [22]. This oxygen pollution was removed on all points of the EPMA profiles. Crosssections were also performed using MEB-FIB FEI HELIOS 600i to observe oxide layers. Tensile tests were performed on a Zwick/Roell Z010 at CIRIMAT using a laser scan micrometer Mitutoyo LSM-506 to measure displacement. Gauge area of tensile specimens was $30 \times 5 \mathrm{~mm}^{2}$ and $1.3 \mathrm{~mm}$ thick and was polished with SiC abrasive paper of P600 grit size. In order to investigate the influence of oxidation on tensile properties, two samples were oxidized at $600{ }^{\circ} \mathrm{C}$ in the Carbolite furnace LHT6/60 for 500 h, before running tensile tests. Rupture surfaces were observed using LEO 435 VP scanning electron microscope.

\section{$\underline{\text { Results }}$}

Microstructure

Figure 1 (a) and (b) show the EBM Ti-6Al-4V alloy microstructures before and after HIP treatment. HIP erases some of the prior $\beta$ grains elongated in the building direction present on as-built microstructure. Figure 1 (c) and (d) show a fine Widmanstätten type lamellar microstructure composed of $\alpha$ lamellae into $\beta$ matrix. HIP induces coarsening of $\alpha$ lamellae ranging from $680 \pm 160 \mathrm{~nm}$ to $2500 \pm 400 \mathrm{~nm}$. Moreover, EBM process induces specific surface roughness, as shown by Figure 1 (a) and (b), with presence of partially melted powder grains inducing a high specific surface [21, 23].

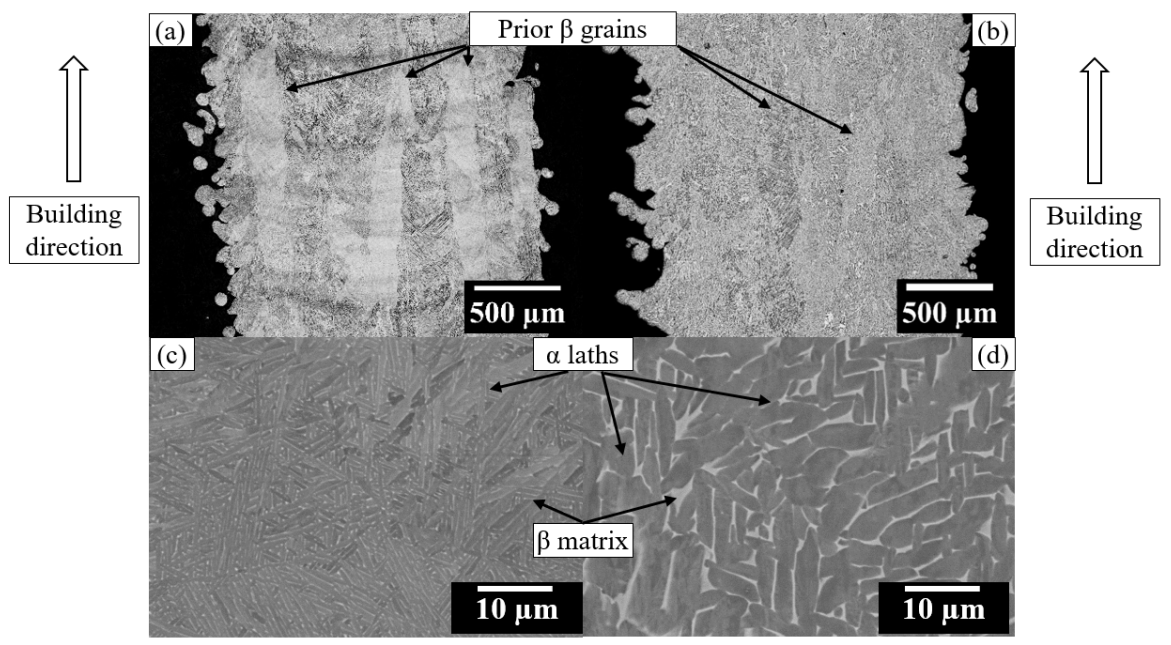

Figure 1: Microstructures of Ti-6Al-4V alloy: (a, c) fabricated by EBM ; (b, d) fabricated by EBM and HIP treated. (a and b) Optical microscopies and (c and d) Scanning Electron Microscopies of Ti-6A-4V.

Oxidation behaviour

Oxidation kinetics at $600^{\circ} \mathrm{C}$ of Ti-6Al-4V alloy fabricated by EBM were characterized by weight gain measurements and are presented in Figure 2 (a). Both as-built EBM samples have larger weight gains than polished EBM samples. Figure 2 (b) also shows that oxide layer thicknesses of as-built EBM samples is slightly higher than polished samples. However, these differences in oxide scale gains than polished EBM samples. Figure 2 (b) also shows that oxide layer thicknesses of as-built EBM samples is slightly higher than polished samples. However, these differences in oxide scale
thicknesses are not large enough to explain the differences of weight gains. When studying LBM alloy 718, Sanviemvongsak et al. showed that larger weight gains of LBM samples were due to the

(C) The Authors, published by EDP Sciences. This is an open access article distributed under the terms of the Creative Commons Attribution License 4.0 (http://creativecommons.org/licenses/by/4.0/). 
higher surface area of as built samples, and to the oxidation of powder grains partially melted at the surface [23]. The same conclusions were reached in a previous study focused on the oxidation of Ti-6Al-4V alloy fabricated by LBM. In this last study, it was shown that powder grains oxidation partially melted at the surface was even more important for Ti-6Al-4V than for alloy 718 , because of the breakaway oxidation kinetics of titanium spheres [21]. In the present study, the role of surface roughness on the oxidation kinetics is confirmed by the fact that all 12 samples fabricated by EBM present the same weight gains once ground with P600 paper (7 samples EBM P600 and 5 samples EBM HIP P600), as shown in Figure 2 (a). In addition, it can be observed that the HIP treatment does not influence the oxidation kinetics of Ti-6Al-4V alloy fabricated by EBM.

(a)

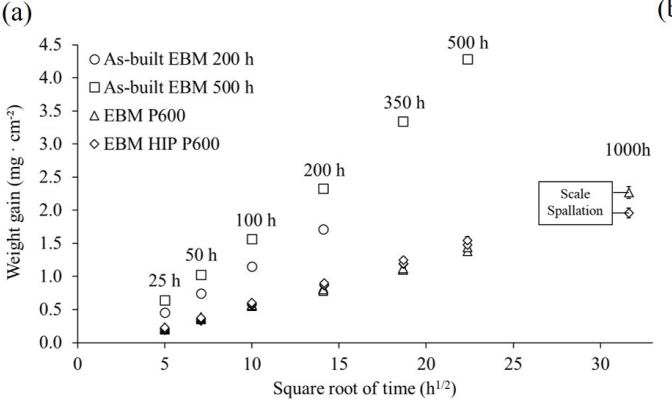

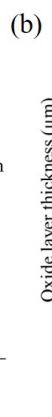

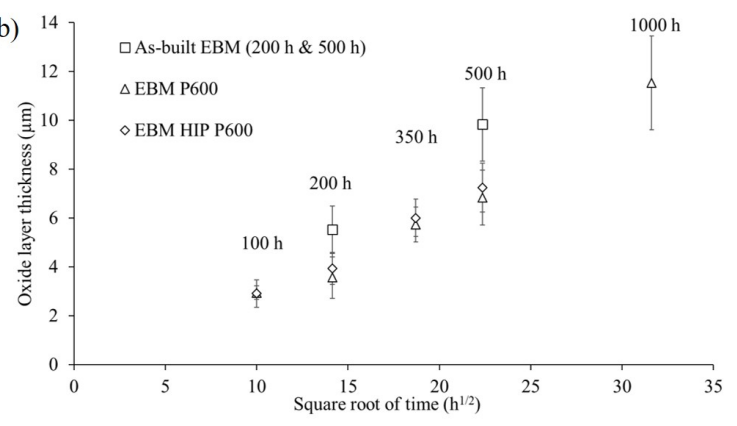

Figure 2: Ti-6Al-4V alloy fabricated by EBM: (a) Weight gains; (b) Oxide layer thicknesses

Figure 3 (a) exhibits a cross-section of a sample oxidized $500 \mathrm{~h}$ at $600^{\circ} \mathrm{C}$. The white layer on the top of the oxide scale is a platinum layer used to keep the integrity of the oxide layer during cutting the samples with an ion beam. The oxide layer shows stratification with several layers separated by pores. The oxide layer seems to be composed of a dense layer between two porous layers. For the sample, oxidized $500 \mathrm{~h}$ at $600{ }^{\circ} \mathrm{C}$, Figure 3 (b) shows facetted crystals with an elongated morphology of about $40 \mathrm{~nm}$ diameter, present at the top of a clearly porous layer. During oxidation, coalescence between independent crystals leads to the formation of larger agglomerates (not shown here). A large density of pores was observed next to and at the oxide/metal interface. This could be the reason for the scale spallation observed for longer oxidation durations.

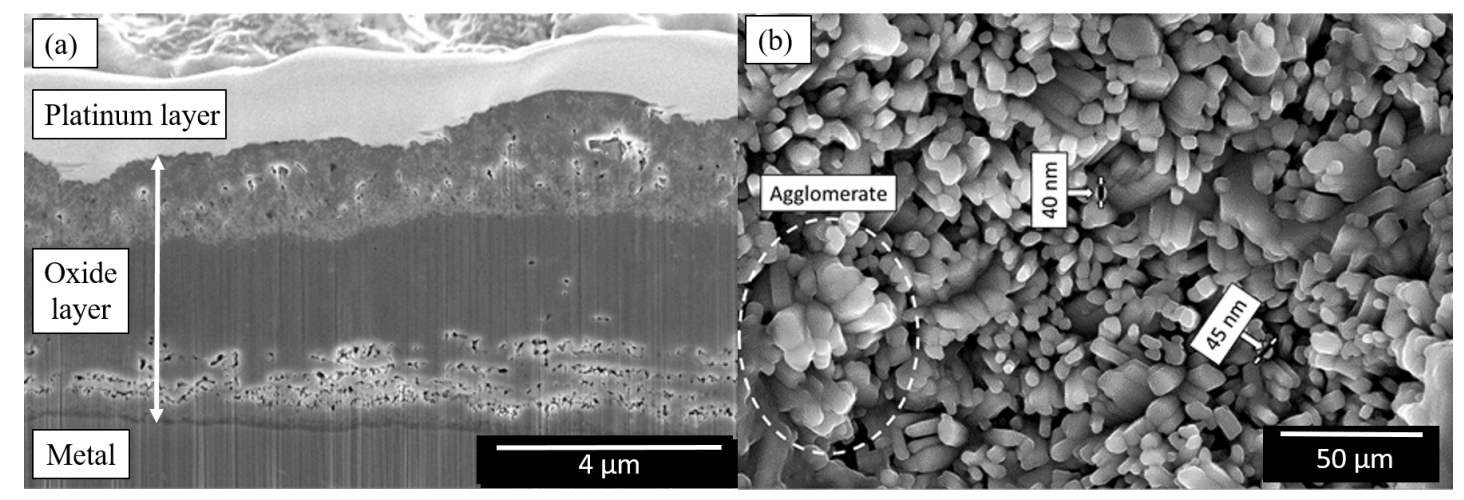

Figure 3: Oxide layer of a Ti-6Al-4V alloy fabricated by EBM oxidized $500 \mathrm{~h}$ at $600{ }^{\circ} \mathrm{C}$ : (a) Cross-section ; (b) Surface morphology

Figure 4 (a) presents six oxygen diffusion profiles measured by EPMA at different locations on the same sample oxidized for $500 \mathrm{~h}$ at $600{ }^{\circ} \mathrm{C}$. It shows that reproducibility is good. A simple diffusion model with the error function represented in $\mathrm{Eq}(1)$ was used to fit the experimental data. This allowed to measure an effective oxygen diffusion coefficient $\mathrm{D}$ and to estimate the oxygen concentration $\mathrm{C}_{\mathrm{s}}$ at the metal/oxide interface. The thickness of the oxygen diffusion zone can be define using the effective oxygen diffusion coefficient and the time with the relation $O D Z=4 \sqrt{D \cdot t}$. Note that $4 \sqrt{D \cdot t}$ corresponds approximatively to the abscissa of the point for which the concentration has increased of $1 \%$ of $\left(C s-C_{0}\right)$. For Ti-6Al-4V alloy fabricated by EBM and oxidized $500 \mathrm{~h}$ at $600{ }^{\circ} \mathrm{C}, \mathrm{D}=(1.1 \pm 0.2) 10^{-17} \mathrm{~m}^{2} \cdot \mathrm{s}^{-1}, \mathrm{C}_{\mathrm{s}}=(23.3 \pm 1.6)$ at $\%$ and the oxygen diffusion zone thickness ODZ is about $18 \mu \mathrm{m}$.

$$
C_{x}=C_{0}+\left(C_{s}-C_{0}\right) \cdot(1-\operatorname{erf}(x / 2 \sqrt{D \cdot t}))
$$

Where $C_{0}$ is the initial oxygen concentration in the metal, $C_{\mathrm{s}}$ is oxygen concentration in the metal close to the oxide/metal interface, $D$ the effective oxygen diffusion coefficient of oxygen in the metal, $t$ the time and $C_{\mathrm{x}}$ the oxygen concentration at the depth $x$.
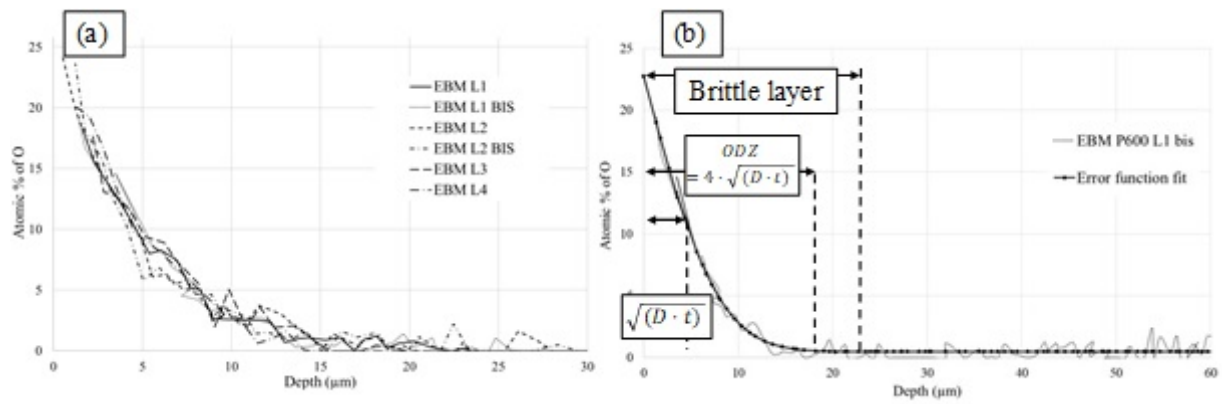

Figure 4: Ti-6Al-4V alloy fabricated by EBM and oxidized $500 \mathrm{~h}$ at $600{ }^{\circ} \mathrm{C}$ : (a) Oxygen concentration profiles ; (b) Error fitting function of oxygen concentration profiles and determination of the oxygen diffusion zone thickness

Figure 2 (a) shows that oxidation follows parabolic kinetics in which can be quantified using Eq (2):

$$
\frac{\Delta W}{A}=\sqrt{k_{p} \cdot t}
$$

where $k_{\mathrm{p}}$ is the parabolic rate constant, $\Delta W$ the weight gain and $t$ the time. $A$ is the surface area of a sample determined from its dimensions. Figure 5 shows that the Arrhenius law, Eq (3), can be used to compare parabolic rate constants $k_{\mathrm{p}}$ obtained in the present work and in the literature at the same or at different temperatures: 


$$
k_{p}=k_{p}^{0} \cdot \exp \left(\frac{E_{a}}{R T}\right)
$$

where $E_{\mathrm{a}}$ is the activation energy, $R$ the gas constant and $T$ the reaction temperature.

Results of this study are in good agreement with the literature. Moreover, Ti-6Al-4V alloy fabricated by EBM presents similar oxidation kinetics as fabricated by conventional manufacturing processes.

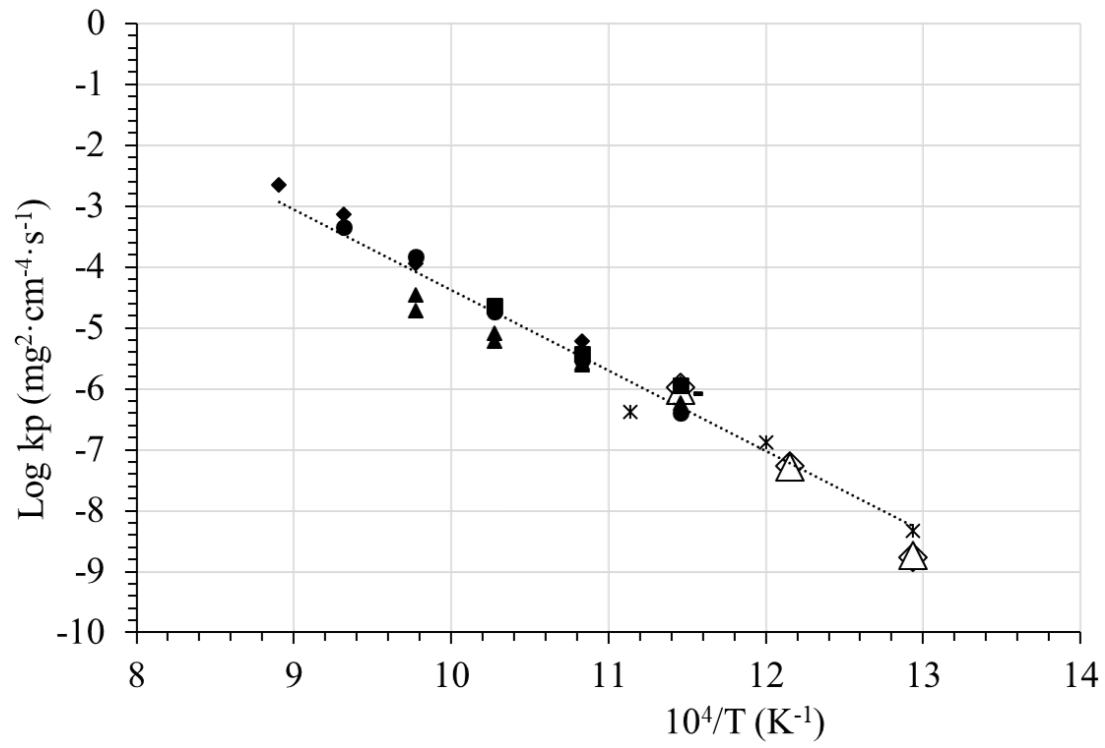

$\diamond$ EBM HIP P600

$\triangle \mathrm{EBM} P 600$

- Guleryuz 2009 (circulating laboratory air)

- Du 1994 (circulating air environment)

- Gaddam 2013 (Ambient

air)

Frangini 1994 (synthetic air)

A Poquillon 2013 (ambient and synthetic air)

* Ciszak 2016 (laboratory air)

Figure 5: Arrhenius plot of parabolic constants $k_{p}$ for the oxidation of Ti-6Al-4V alloys $[16,17,19,24-26]$

Tensile tests

The effect of oxidation on mechanical properties was studied using uniaxial tensile tests. Figure 6 (a) shows tensile tests of Ti-6Al-4V alloy fabricated by EBM and polished with P600 grit size. Results concerning unoxidized and oxidized specimen during $500 \mathrm{~h}$ at $600{ }^{\circ} \mathrm{C}$ are given too. During the tensile test, spalling of the oxide layer produces flakes which pass in front of the laser measuring the length of the sample and produce fake deformation jumps on the tensile curves, Figure 6 (a). For the sample size and the oxidation conditions studied, it appears that oxidation significantly reduces the elongation at break but does not influence the yield strength and the ultimate tensile strength, as shown in Figure 6 (a). Study of the fracture surfaces shows an external area with a brittle fracture mode and an inner section with a ductile behavior with cupules, as shown on Figure 6 (b). Oxide scale has spalled during the entire test and was not observed on fracture surface observations. The depth of brittle rupture is $\approx 24 \pm 4 \mu \mathrm{m}$. It can be compared with the depth of zone affected by oxygen (Fig. $4 \mathrm{~b}$ ).
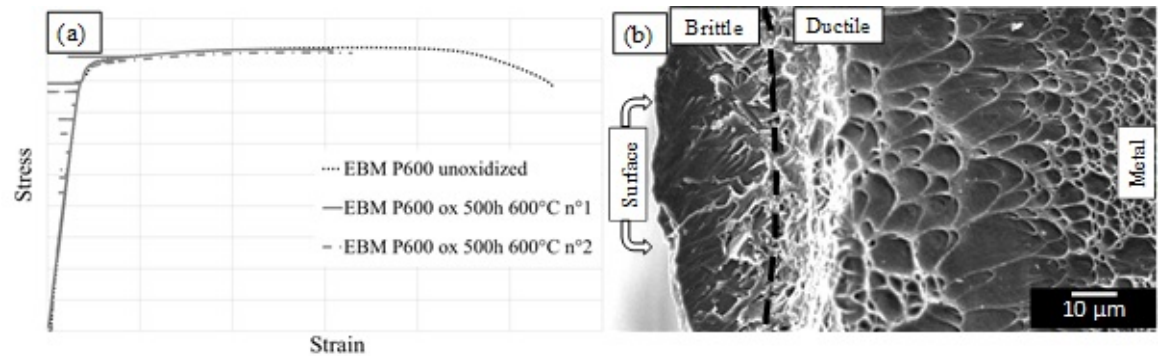

Figure 6: Ti-6Al-4V alloy fabricated by EBM: (a) Tensile test curves before and after $500 \mathrm{~h}$ of oxidation at $600{ }^{\circ} \mathrm{C}$; (b) Rupture surface of an EBM sample oxidized $500 \mathrm{~h}$ at $600{ }^{\circ} \mathrm{C}$

\section{$\underline{\text { Discussion }}$}

EBM Ti-6Al-4V alloy presents a fine lamellar microstructure composed of submicronic $\alpha$ laths into a $\beta$ matrix. HIP treatment is used to reduce porosity and induces the coarsening of $\alpha$ laths. As seen on weight gains and oxide layer thickness measurements, despites its large effect on the alloy microstructure, HIP does not influence the oxidation behaviour, Figure 2. Cross-sections observed with SEM show the presence of pores into the oxide layer and at oxide/metal interface. Tensile tests and SEM observations of fracture surfaces shows that the oxide layer quickly spalled during the tensile SEM show the presence of pores into the oxide layer and at oxide/metal interface. Tensile tests and SEM observations of fracture surfaces shows that the oxide layer quickly spalled during the tensile
test. EPMA measurements were used to determine the oxygen diffusion zone which has an influence on mechanical properties. Tensile tests confirmed that oxygen diffusing into the metal decreases the elongation at break and changes the rupture mode from ductile to brittle. The brittle fracture zone thickness is slightly higher $(\approx 23 \mu \mathrm{m})$ than the oxygen diffusion zone thickness which can be determined by EPMA $(\approx 18 \mu \mathrm{m})$, Figure 4 (b) and Figure $6(\mathrm{~b})$. This shows that the critical amount of oxygen necessary to embrittle the alloy is much lower than the minimum amount of oxygen which can be measured accurately by EPMA. It is possible to use the diffusion model to estimate this critical value. The calculated diffusion profile allowed to approximate the oxygen concentration at $23 \mu \mathrm{m}$ deep (Fig $4 \mathrm{~b}$ ). This value is about $0.5 \mathrm{at} \%$. It can be compared to the result obtained by Yan et al. determined a drop of ductility for an oxygen concentration above 0.33 mass $\%(\approx 1$ at $\%)$
into the metal [27].

\section{Conclusion}

Additive manufacturing processes commonly make use of HIP. This high temperature treatment under pressure allows to reduce porosity but also induces microstructure evolutions. It was shown that HIP strongly influences the microstructure of TA6V. Nevertheless, for EBM Ti-6Al-4V alloy, HIP does not influence oxidation kinetics. The oxide layer obtained after $500 \mathrm{~h}$ at $600{ }^{\circ} \mathrm{C}$ is $7 \pm 1$ $\mu \mathrm{m}$ thick with prismatic needles at its top. This oxide layer presents an inner dense layer between porous layers. Pores in the inner part delimitate oxide scale sublayers which may induce spallation during tensile tests. The oxygen diffusion zone in the metal drastically reduces the elongation at break and changes the rupture mode from ductile to brittle. It was shown that the oxygen diffusion zone which can be measured with the accuracy of EPMA, $\approx 18 \mu \mathrm{m}$, is slightly lower than the observed brittle zone which is about $23 \pm 4 \mu \mathrm{m}$ after $500 \mathrm{~h}$ at $600^{\circ} \mathrm{C}$. Using diffusion modelling, the critical oxygen content at the transition between the brittle and ductile failure was estimated to be lower than 1 at $\%$ determined by Yan et al. [27].

\section{Acknowledgements}

This work falls within the framework of the Andduro project hosted by the French Institute of Technology IRT Saint Exupery, supported by Occitanie Region and industrial partners. The authors gratefully acknowledge Claudie Josse and Sophie Gouy (UMS Castaing) for their technical assistance about FIB cross-section observations and EPMA measurements, respectively.

\section{$\underline{\text { References }}$}

[1] R.R. Boyer, An overview on the use of titanium in the aerospace industry, Materials Science and Engineering a-Structural Materials Properties Microstructure and Processing, 213 (1996) 103114 . 
[2] H.L. Du, P.K. Datta, D.B. Lewis, J.S. BurnellGray, High-temperature corrosion of Ti and Ti-6Al-4V alloy, Oxidation of Metals, 45 (1996) $507-527$.

[3] P. Kofstad, K. Hauffe, H. Kjollesdal, Investigation on the Oxidation Mechanism of Titanium, Acta Chemica Scandinavica, 12 (1958) $239-266$.

[4] H. Shipley, D. McDonnell, M. Culleton, R. Coull, R. Lupoi, G. O'Donnell, D. Trimble, Optimisation of process parameters to address fundamental challenges during selective laser melting of Ti6Al-4V: A review, International Journal of Machine Tools and Manufacture, 128 (2018) 1-20.

[5] C. Körner, Additive manufacturing of metallic components by selective electron beam melting — a review, International Materials Reviews, 61 (2016) 361-377.

[6] X. Gong, T. Anderson, K. Chou, Review on Powder-Based Electron Beam Additive Manufacturing Technology, (2012) 507-515.

[7] M.F. Zaeh, M. Kahnert, The effect of scanning strategies on electron beam sintering, Production Engineering, 3 (2009) 217-224.

[8] L.E. Murr, E. Martinez, K.N. Amato, S.M. Gaytan, J. Hernandez, D.A. Ramirez, P.W. Shindo, F. Medina, R.B. Wicker, Fabrication of Metal and Alloy Components by Additive Manufacturing: Examples of 3D Materials Science, J. Mater. Res. Technol., 1 (2012) 42-54.

[9] M. Koike, K. Martinez, L. Guo, G. Chahine, R. Kovacevic, T. Okabe, Evaluation of titanium alloy fabricated using electron beam melting system for dental applications, Journal of Materials Processing Technology, 211 (2011) 1400-1408.

[10] T. Scharowsky, V. Juechter, R.F. Singer, C. Körner, Influence of the Scanning Strategy on the Microstructure and Mechanical Properties in Selective Electron Beam Melting of Ti-6Al-4V, Advanced Engineering Materials, 17 (2015) 1573-1578.

[11] S.L. Sing, J. An, W.Y. Yeong, F.E. Wiria, Laser and electron-beam powder-bed additive manufacturing of metallic implants: A review on processes, materials and designs, Journal of Orthopaedic Research, 34 (2016) 369-385.

[12] S.S. Al-Bermani, M.L. Blackmore, W. Zhang, I. Todd, The Origin of Microstructural Diversity, Texture, and Mechanical Properties in Electron Beam Melted Ti-6Al-4V, Metallurgical and Materials Transactions A, 41 (2010) 3422-3434.

[13] K. Kakehi, T. Hashimoto, Influence of oxidation on mechanical properties of the heat-resistant titanium alloy DAT54, J. Jpn. Inst. Met., 72 (2008) 819-824.

[14] D.A. Brice, P. Samimi, I. Ghamarian, Y. Liu, R.M. Brice, R.F. Reidy, J.D. Cotton, M.J. Kaufman, P.C. Collins, Oxidation behavior and microstructural decomposition of Ti-6Al-4V and Ti-6Al4V-1B sheet, Corrosion Science, 112 (2016) 338-346.

[15] E. Dong, W. Yu, Q. Cai, L. Cheng, J. Shi, High-Temperature Oxidation Kinetics and Behavior of Ti-6Al-4V Alloy, Oxidation of Metals, 88 (2017) 719-732.

[16] H.L. Du, P.K. Datta, D.B. Lewis, J.S. Burnellgray, Air Oxidation Behavior of Ti-6al-4v Alloy between 650-Degrees-C and 850-Degrees-C, Corrosion Science, 36 (1994) 631-642.

[17] S. Frangini, A. Mignone, F. de Riccardis, Various aspects of the air oxidation behaviour of a Ti6Al4V alloy at temperatures in the range $600-700{ }^{\circ} \mathrm{C}$, Journal of Materials Science, 29 (1994) 714-720.

[18] H. Güleryüz, H. Çimenoğlu, Effect of thermal oxidation on corrosion and corrosion-wear behaviour of a Ti-6Al-4V alloy, Biomaterials, 25 (2004) 3325-3333.

[19] R. Gaddam, B. Sefer, R. Pederson, M.L. Antti, Study of alpha-case depth in Ti-6Al-2Sn-4Zr-2Mo and Ti-6Al-4V, IOP Conference Series: Materials Science and Engineering, 48 (2013) 012002.

[20] Y. Zhou, S.F. Wen, B. Song, X. Zhou, Q. Teng, Q.S. Wei, Y.S. Shi, A novel titanium alloy manufactured by selective laser melting: microstructure, high temperature oxidation resistance, Materials \& Design, 89 (2016) 1199-1204.

[21] A. Casadebaigt, J. Hugues, D. Monceau, Influence of Microstructure and Surface Roughness on Oxidation Kinetics at 500-600 ${ }^{\circ} \mathrm{C}$ of Ti-6Al-4V Alloy Fabricated by Additive Manufacturing, Oxidation of Metals, (2018).

[22] H.P. Tang, M. Qian, N. Liu, X.Z. Zhang, G.Y. Yang, J. Wang, Effect of Powder Reuse Times on Additive Manufacturing of Ti-6Al-4V by Selective Electron Beam Melting, JOM, 67 (2015) 555563.

[23] T. Sanviemvongsak, D. Monceau, B. Macquaire, High temperature oxidation of IN 718 manufactured by laser beam melting and electron beam melting: Effect of surface topography, Corrosion Science, $141(2018) 127-145$.

[24] H. Guleryuz, H. Cimenoglu, Oxidation of Ti-6Al-4V alloy, Journal of Alloys and Compounds, 472 (2009) 241-246.

[25] D. Poquillon, C. Armand, J. Huez, Oxidation and Oxygen Diffusion in Ti-6al-4V Alloy: Improving Measurements During Sims Analysis by Rotating the Sample, Oxidation of Metals, 79 (2013) 249-259.

[26] C. Ciszak, I. Popa, J.-M. Brossard, D. Monceau, S. Chevalier, NaCl induced corrosion of Ti-6Al-4V alloy at high temperature, Corrosion Science, vol. 110 (2016) pp. $91-104$.

[27] M. Yan, M.S. Dargusch, T. Ebel, M. Qian, A transmission electron microscopy and three-dimensional atom probe study of the oxygen-induced fine microstructural features in as-sintered Ti6Al-4V and their impacts on ductility, 2014. 